\title{
The Effect of Performance Appraisal in an Organizatin
}

\author{
Mrs. Ekwochi Eucharia Adaeze, (MBA, B.SC.) Aipma \\ Department of Business Administration \\ Enugu State University of Science and Technology, (ESUT), Enugu
}

\begin{abstract}
This study is on the effects of performance appraisal on productivity in an organization and it is geared towards examining the effects of performance appraisal on the productivity of employees in organization. The objective of this study is to investigate the performance appraisal techniques adopted in an organization, to examine the usefulness of performance appraisal programme in an organization, to find out the various environmental variables affecting performance appraisal programs in an organization, to identify the pitfall associated with performance appraisal exercise and provide solutions to them. In the course of this study, data were collected from primary and secondary sources and it was analyzed. The researcher made use of survey design. In view of the findings, it was discovered that participation of employees in appraisal exercise and the use of performance appraisal resulted to an increase in output to the organization and higher standard of living to the employee because of promotion given and other necessary reward that motivated the employee to work hard. At the end of this work the researcher was able to conclude that problem with the organization's appraisal system lies with implementation rather than method. Consequently, since the intention of the research is not to recommend an entirely new method but to enhance the relationship between the currently used method and its objectives, the researcher conclusion is there summed up in the phrase. Better implementation of the organization's appraisal method is needed so as to be able to match practice with purpose on an intensive advice that the organization should provide an intensive training programme for appraisal. my final conclusion draws on the major highlight of the study of the revelation that subordinates are not involved in setting goals and objectives on which they are appraisal.
\end{abstract}

Key Words: Performance, Appraisal, Organization and effects 


\section{Introduction}

The principal purpose of acquiring human resources in any organization is to aid in the actualization of the organizational objectives. However, productivity targets vary from reality or actual performance because of ranges of variables. Environment: human technology, organizational and so on. The task of management is on these variables which have constituted themselves as obstacles to productivity in opportunities for productivity. Hence herald a tedious task of personnel managers in any organization. Certain fundamental question needs to be asked. How do we acknowledge deviation?

What should we focus on as fundamental in our assessment?

When should we appraisal and how frequently should it be done?

Is there any correlation between performance appraisal and productivity?

How do we appraise employee's performance maximum productivity?

These and many more questions keep on begging for attention and or solution, most personnel foundation are contingent upon performance appraisal. Performance appraisal helps to evaluate training needs, determine the equitability of compensation package, serve as basic of executive the maintenance and separating functions etc. yet the veritable positives of performance appraisal in personnel management function is being riddled or abused. The NBL and other organization in Nigeria have persistently shoe with rigor and vigor to effectively and efficiently utilized performance appraisal as an instrument or a basic ingredient for productivity.

\section{Statement of Problem}

In Nigeria most of the performance appraisal exercise /program are not well designed and focused. Management of organization tends to view it as a punitive measure. This makes it lose its objective sand focus, performance appraisal no longer seek to actualize its objective of correcting deviations, hence increasing productivity and jettison all hindrance that tends to hinder productivity. But it is being used as and jettisons all hindrance that tends to hinder productivity. But it is being used as a tool for subordination oppression, victimization and 
exploitation. Despite the veritable return at performance appraisal to many organizations, the societal value system has subdued it objectivity and its attendant's outcomes. This makes most of our performance more subjective than objective.

\section{Objective of the Study}

The objective of this study is:

(a) To investigate the performance appraisal techniques adopted in an organization.

(b) To examine the usefulness of performance appraisal programme in an organization.

(c) To find out the various environmental variables affecting performance appraisal programs in an organization

(d) To identify the pitfall associated with performance appraisal exercise and provide solutions to them.

\section{Review of Related Literature}

According to Ubaka 1978:166 said that THE CONCEPT OF PERFORMANCE APPRAISAL in every work setting, performance need to be evaluated, as all efforts are supposed to be geared towards achieving organizational objectives. Mayfield (1960:26) seen performance appraisal as an attempt to thinks clearly about each person's performance and future prospects against the background of his/her total work situation. In the same direction Ubaka A (1976:188) define it as a system used to review the individuals performance during a set period to identify his areas of strength and weakness and establish target for his/her for achieving within the overall corporate objective of the organization. He assets that performance evaluation is not just an inquisition but a means to developing the employees on his/her job. Performance appraisal is a process of formal evaluation of employee's action over a period of not more than a year. It involves three processes a subordinate is assigned a problem area and gains experience in recognizing crucial faces of it.

Gradually assumes primary responsibility for his areas smooth functioning and receives a performance evaluation from his superior (Platz A 1975:75) Monappe cital (1998:208) copiers that "performance 
appraisal is a systematic and objective way of judging the relative wrath or ability of an employee in performing hi task it primary help to identify those who are performing their assigned task well and those who are not, and the reason for such performance. This depicts that performance appraisal is not end itself but a means to an end, i.e it seeks not to be judgment but corrective performance appraisal is important both to the organization, it provides information about job performance and potentials. It helps responsibilities on the basis of competence and to plan relevant training and development it also enable the organization to reward the individual adequately and to learn of his views and aspirations concerning his own career. To the employee, appraisal help employee to know the role expected of him/her in the achievement of the corporate objectives. It also helps the employee to know the standard of performance required so that they can evaluate their own performance. Performance appraisal also helps the employee to appropriate his prospects and enable employee to organize him/herself development Platz, A 175:76

The importance of performance appraisal can be condensed thus: it is necessary in order to allocate resource in a dynamic environment, reward employees, give employee feedback about their work, and maintain fair relationship within groups (each and develop employees and comply with equal opportunity regulations. Appraisal systems are therefore necessary for proper management and for employee development (Davis Kenth 1981:474). Objective of performance appraisal various scholar and practicing managers have viewed the objective of performance appraisal in varied ways. Some conclude that it is a punitive /judgmental, which others view it as a corrective measure.

Kindall, A.F. et al (1963:97) states that "approval of performance is geared towards developing people in two ways:

Providing the organization with people qualified to step into higher positions as they open up.

Serving as a help to the individual who wished to acquire the knowledge and ability he needs to become eligible for a higher job: Mcaregor D.(91972:5) stated three performance appraisal plans designed to meet three objectives. 
To provide systematic judgment to back up salary increases, promotion, transfer.

To tell a subordinate how he is doing and suggested needed changes in his behaviour attitudes skills or job knowledge to let him/her know where he/she stand with the boss

$\square$ Use as a basis for the coaching and counseling of the individual by the superior.

\section{Appraisal procedure therefore seeks to provide answers to questions such as:}

How am I doing?

Where do I go from here?

What are my strength and weakness?

What do I need to move from here to there?

These question seen to be a most recurrent action of almost every organizational member providing answers to them will be of great value to the organization, as employee will always be part and weighted down by these questions: appraisal provides an inventory of persons resources, and serve as a meant for testing personnel procedures. According to APPLE R 1959:285 said that it benefits of performance appraisal is that both the employee as well as the organizations benefit from performance appraisal. According to apple by R (1959: 285), an emp0loyee benefits from appraisal when he understands his strength and weakness and his potential for future development is indicated.

The further listed a catalogue of benefits an employee's gain as a result of appraisal thus.

- Aids in increasing morale

- Increasing impudence in fairness of management

- Aid in uncovering hidden talent

- Reveals covered weaknesses

- Serve as a base for future growth

- Aids increasing motivation

In the same vein, Apple by R. further states that an organization benefits from appraisal "of information obtained about total management 
resources available for planning and deciding on the needs of training and management development".

Therefore an organization benefits from appraisal in the following ways:

a) It facilitates recognition and stimulation of hidden talents.

b) It enables the management to know the employee within the organization.

c) It enables the management to become aware of the strength and weakness of its staffs.

d) Provides accumulated records from which personnel decision may be base.

e) It helps to improve relation between management and staff.

f) Provides information for inservice training in synopsis, both the individual and the organization that embark on appraisal seeks to asses for success i.e be love in continuous improvement.

\section{Pitfalls of performance appraisal:}

According to Oberg W (1981:290) formal performance appraisal is familiar to most Managers either from painful personnel experience or from the growing body of critical literature". In his view, performance appraisal programme demand too much from supervisions. They obviously require at least periodic supervision observation of subordinate's performance. The typical first time supervision can hardly know in a very adequate way which each of his/her numerous subordinates are doing. Piguish, Petal (1981:291) observed that all student of rate is i.e being either too lenience or too tough constitutes a limitation to successful appraisal". Consequently, standard and rating tend to vary widely an often, unfairly. Some departments have tightly competent people, others have low competent people. As a result employee's receives high or low rating depending on the competence or lenience of the rate. Personal values and bias also limits the effectiveness of the appraisal programs. This term replace organizational standards. 
However this does not mean that appraisal lacks standards but that the standards they are sometimes wrong ones. The situations where a subordinate may be unfairly rates so that he will not promoted out of the rate department Ubaka $\mathrm{A}(1981)$ believe more often than not some right bias indicates favoured treatment for some employee". There is also a communication gap between the employee and the appraisal by which employee think they are being judge are different from these, their superior actually use improving performance and developing people are two of the most common appraisal plan goals".

It seems obvious that the appraisal process cannot go for forward attaining the goals unless there is effective communication between the evaluator and the person being evaluated. No performance appraisal system of causes can be very effective for management or any other purposes until expected of them and by what criteria they are being judged one of the most notable limitation of performance appraisal system of causes can be very effective for management decisions, organizational development or any other purposes until expected of the most notable limitation of performance appraisal system is the complete reluctance of the supervisors to lake the time and trouble to go the rudiments of preparing the periodic appraisal of each of the subordinates and especially to discuss the result with them.

There may be sound reasons according to McGregor for this reluctance, as many supervision are uncomfortable when they are placed in the position of playing with God. Another limitation that operators practice is that performance appraisal is so often made recorded filed and forgotten. Yet personnel decisions are made as a late time without reference to those appraisal, despite the fact that the whole purpose of performance appraisal is to improved the employee's performance by promotion, favourable transfer merit wage and salary increase. Thus, if performance appraisal can be more clearly related to performance standards expected on each job, it is also likely to be criticized as wholly subjective because such traits as dependability and initiative are being evaluated. Another limitation of performance appraisal is the difficulty of establishing performance standard for professionals and technical employees such as scientists and engineers. In spite of these 
limitation and due to the absent of an alternative system performance appraisal as presently practiced will continue to be used.

\section{Techniques of performance appraisal}

Formal performance appraisal programme have often yielded unsatisfactory results. This may be partly due to the manner which and partly as a result for failure to close a particular approach or method that most adequately suit the objectives. There are many techniques of appraisal some of these are simple while others are more complex there by, requiring well trained appraise who can effectively use them.

The most commonly used appraisal techniques include:

(a)
Field review

Essay appraisal

Critical incident appraisal

Ranking method

Assessment

Work standards approach

Forced-choice rating

Graphic rating scale

Check list method

\section{MODE}

- $\quad$ Subordinate participate in the setting of performance targets increases the commitment to and success in establish them.

- Constructive attitudes by supervisor and outcome not predetermined.

- Participation in discussion and decision of the subordinate should be of high level.

- $\quad$ Material approach to solving problem

- $\quad$ Opportunity for self appraisal encourage son that managers can be spared to develop himself.

- $\quad$ Appraisal must be a regulate activity of the organization (e.g end of a finished product car furniture) refer to suit the needs of the individuals or work groups. 
- $\quad$ Salary review must be separated schemes that try to deal salary will not work out effectively. In the case shown below are part of performance:

\section{Management by objective (MBO)}

To accomplish anything, know whether or not you have done so, compare achievement, with objectives. MBO is an effort to be fair and reasonable to predict performance and judge it more carefully, and presumable to provide individuals with an opportunity to $b$ self motivating by setting their own objectives Konntz and O'Donald noted that one of the most important and fascinated development in the management scene has been the establishment of programme of management by objectives. Realizing how difficult and cumbersome, it is for managers to accomplish ambiguous goals quantitatively or qualitatively objectives are set for managers which they are required achieve.

Peter Drucker, a proponent of management by objectives is perhaps that it makes it possible for a manager to control his own performance. $\mathrm{He}$ further asserts that self control means stronger motivation implying the describe to always achieve or do the best rather than just do, fast enough to by. He believes that the importance of MBO is higher performance goals and also broader vision. Doglas McGregor, on his part said that one of the cause of failures of appraisal system stems from the facts that supervisors dislike plying God that is making judgment about another man's worth. He recommended instead than an individuals should set his own goals, checking them out with his superior, and should use the appraisal sessions as a counseling device. Thus, the subordinate achieve his own goals instead at dehumanized inspector of products.

A critic of the MBO programme Harry Levinson, while not agreeing with McGregor that the failure of appraisal steam from playing God or feeling in human said that managers experience their unconsciously is felt to be hurting or destroying the other person. According to him, MBO process put the reporting manager in much the same position as a rate in a muze, who has choice between only two alternatives, he further stressed that because the technique is based on a reward punishment 
psychology; the process of $\mathrm{MBO}$ in combination with performance appraisal is self defeating. Arguing further, he said that method simply serves to increase pressure on the individual.

However, Levinson Harry in all critics against MBO does not reject the process itself but does argue that the technique can be improved by examination of underlying assumption and by considering the individual personal goals first. In spite of criticism about MBO, the most effective objective coaching counseling and motivational purpose call for the use of MBO approach if it involves real participation, appears to be most likely to an inner commitment to improved performance. Also, it performance appraisal information is to be communicated to subordinate either in writing or in an interview, MBO proves to be one of the most effective techniques.

Other advantages $\mathrm{MBO}$ includes:
a)
Through MBO, assessment becomes an integral part of the organizational planning and continuo system.
b) The commitment is a powerful motivational force.
c) The emphasis is no work achievement and not on the main personal characteristics.
d) The cycle is highly participative
e) It goes further towards the ideals of self appraisal and self direction.

However, MBO is still not without disadvantages. Some of its disadvantages includes

(a) With MBO, the total process, especially the counseling, is very time consuming.

(b) Special circumstances (e.g) change in economic environment) too often make the objective unrealistic

(c) It encourages an emphasis on the short term the selection activity.

(d) Research shows that many individual are not self directive they want to be told what to do. 
(e)

It can degenerate into a pseudo - participative exercise, where the realities of direction are firmly with management.

\section{Fundamental of successful appraisal (programme)}

According to Appleby R (1973:120) the following are guidelines of good appraisal programme.

- All levels of management, unions and employees should accept to scheme and understand the purpose and nature.

- Line managers should shoulder the final responsibilities of appraisal and they should properly implement the scheme and the system reviewed periodically and necessary changes.

According STONE R (1991:80) also says that performance appraisal versus productivity is the sole aim of performance appraisal, is correct deviation ( $\mathrm{E}$ any from set deviations it is not primitive in nature it seeks to dictate variance from standard, hence provide measure via which actual performance can be improved upon. This measure could be either training the step to jettison hindrance that hinders employee productivity.

\section{Research Design}

In this research work, the researcher made use of survey design and also make us of both primarily and secondary data. The primary data used were personal interviews, observations and structured questionnaires

The secondary data were collected through the use of the following libraries.

- Personal library

- Enugu State Library and other writer ups by other researchers.

\section{Discussion of findings}

Among the objective of this study was to find out why most of the organizations fail in appraisal the performance of their employee. It means human resources, these resource are what human beings used in 
the production process, they could still be called employees or provide of labour. Again this research work shall be of great benefit to the management of any organization this in business if they apply the recommendation, prefer solutions which when applied will improve the role performance appraisal plays in, increasing productivity. It is also beneficial to other firms in various industries as it will avoid the opportunity to adequate understand, appreciated and utilize performance appraisal for the turnaround of the organization for the better.

In every work setting, performance needs to be evaluated as all efforts are supposed to be geared toward achieving organizational objectives. Performance appraisal is important both to the organization, it provides information about job performance and potentials.

No wonder Knidau, A.F. et al (1963:97) states that approval of performance is providing the organization with people who are qualified to step into higher positions as they open up the way.

\section{Recommendations}

In view of the findings, the researcher therefore gives the following recommendations that the performance appraisal in the company should be divorce from salary action separate appraisal should be held for different purpose. A situation where a manager would be helping on employee's to improve his performance while at the same time presiding as a judge over the same employee's salary level is only idealistic and impartial.

\section{Conclusion}

At the end of this project work the researcher was able to conclude that problem with the company's appraisal system lies with implementation rather than method. Consequently, since the intention of the research is not recommend an entirely new method but to enhance the relationship between the currently used method and its objectives, the researcher conclusion is there summed up in the phrase. Better implementation of the company's appraisal method is needed so as to be able to match practice with purpose an intensive advice the company to provide an 
intensive training programme for appraisal my final conclusion draws on the major highlight of the study of the revelation that subordinates are not involved in setting goals and objectives on which they are appraisal.

\section{Reference}

Harold Mayfield (1960): Defense of Performances Appraisal, March April No 60206 pp.26.

Nwachukwu C.C (1980): Personnel administration Concept and Situatio,. (Published work).

Rogers Meyer (1981): Personnel Administration, McGraw Hill Ltd., $8^{\text {th }}$ Edition pp 290.

Loan et al (1968): New Context of Performance Appraisal, London PD. Publication LTD $2^{\text {nd }}$ Edition, pp.76 - 90.

Davis K (1981): Modern Business Administration, John Willey and Sons pp. 80.

Agbo, O.G (2002): Human Resources Management, Onitsha. Base Printing and Publishing Limited.

Onyeka, K.J (1999): Business policy an introductory analysis, Enugu, New GenerationBooks. 